\title{
Racial Prejudice in a Search Model of the Urban Housing Market ${ }^{2}$
}

\author{
Paul N. Courant \\ Department of Economics and Institute of Public Policy Studies,
} The University of Michigan, Ann Arbor, Michigan 48109

Received May 12, 1976; revised December 21, 1976

\begin{abstract}
A simple model of buyer search in an urban housing market is employed to demonstrate that if some whites are unwilling to sell housing to blacks competitive equilibria in which blacks pay more for housing than whites are sustainable. The model is also used to consider a number of issues in the literature on housing discrimination. Most important, it is shown that in equilibrium the housing market will be racially segmented under a wide variety of conditions.
\end{abstract}

\section{INTRODUCTION AND SUMMARY}

There are few areas in which economic theory explains economic reality more poorly than in the relationship between housing prices and race. Both casual and formal empiricism strongly indicate that in many urban areas blacks receive housing services on terms inferior to those obtained by whites. ${ }^{2}$ Yet the housing market appears to be competitive, and a number of models of competitive markets in which there is assumed to be white prejudice against living near blacks imply that competitive equilibrium in such markets will only be established when blacks receive housing on terms more favorable than those obtainable by whites. ${ }^{3}$ Two solutions to this apparent contradiction have received wide attention in

${ }^{1}$ Conversations with John R. Chamberlin, Alan V. Deardorff, and Sidney G. Winter were instrumental in the preparation of this paper. Harvey E. Brazer, participants in the Public Finance Seminar at The University of Michigan, and participants in the May 1975 conference of the Inter-University Committee on Urban Economics made valuable comments on an earlier draft. Edwin S. Mills made valuable comments on the penultimate draft.

${ }^{2}$ See, for example, Kain and Quigley [8], King and Mieszkowski [10], Rapkin [13], and Muth [11].

${ }^{3}$ For early statements of such results see Becker [2], Bailey [1], and Muth [11]. Courant [3] and Rose-Ackerman [14] have extended these results to explicitly spatial models. The literature is summarized in Courant and Yinger [4]. 
the literature. Becker [2] and Haugen and Heins [6] have suggested that we have observed a persistent disequilibrium, deriving from the fact that the rate of growth of the black population has been faster than that of the white. Unfortunately, this rate of growth hypothesis is seriously incomplete, in that it does not explain why black immigrants to northern cities should do any worse in the housing market than any other immigrant group. This defect can be corrected if it is assumed that blacks are prevented, by some mechanism, from acquiring housing in the white part, of the city. Kain [7] and Kain and Quigley [8] have argued that whites force blacks to pay a premium to live in white neighborhoods, but they have not explained how this would lead to a scgmented market unless all whites exhibit such discrimination even where there are profits to be made from dealing with blacks.

The purpose of this paper is to develop a model of the housing market in which the long-run competitive equilibrium, if there is aversion among only some whites to living with and dealing with blacks, may involve a segmented market with all blacks receiving housing on terms inferior to those obtained by whites. That prejudiced whites would like the market to be organized in this way has never been disputed. The problem, succinctly stated by Muth [11] is that in a competitive market collusion must break down and direct aversion to dealing with blacks will not be a profit maximizing mode of behavior if some whites are not averse to dealing with blacks. In Sections 2 and 3 a simple model of housing search will be employed to demonstrate that aversion on the part of some whites to dealing with blacks can lead to equilibria in which blacks pay higher prices than whites for housing. Ncither collusion nor unanimity of prejudice are required. In Section 4 , the discussion will be expanded to include real estate agents and arbitrageurs (blockbusters). Finally, in Section 5, some welfare implications will be discussed.

Two important sets of issues which are potentially relevant to the discussion will not be dealt with in this paper. The discussion takes place only in the context of the market for owner-occupied single-family housing. While most of the material in the search model will also apply directly to rental housing, the material on real estate agent behavior will not apply as directly. Furthermore, the market for rental housing in multiunit buildings poses the added problem that the landlord, at least with respect to his building, is not a perfect competitor. A thorough discussion of the implications of this fact can be found in Yinger [17].

\section{THE HOUSING SEARCH MODEL}

\subsection{Buyer Search in a Housing Market without Racial Prejudice}

The model of the housing market in which the subsequent discussion will take place has the following properties: 
1. Houses are characterized by a joint distribution of a multitude of characteristics. No explicit functional form for this distribution is assumed.

2. The prices of all of the characteristics are in perfect "hedonic" equilibrium, and are known to all. Thus if the vector of (annual rental) prices is $P$ and the vector of characteristics is $H_{i}$ for house $i$, the yearly value of house $i$ will simply be $P \cdot H_{i}$. This price will be posted and it is at the capitalized value of this price that the seller will sell.

3. Buyers have utility functions defined on a consumption commodity and the vector of housing characteristics $H$. On entering the market, they compute the utility that they would obtain if they found a house with just the vector $H$ which maximized their utility at prices $P$ and their incomes.

4. Buyers also know the multivariate distribution of housing units as a function of the characteristics. Knowing their utility functions, knowing this distribution, and assuming that they have prior information sufficient to screen out houses below some positive utility level, they compute a distribution of utilities which would be derived from purchasing houses in the market. This distribution is denoted $f(V)$, where $V$ is utility derived from housing. It meets the standard condition that

$$
\int_{\underline{V}}^{\bar{V}} f(V) d v=1,
$$

where $\underline{V}$ is the lowest utility associated with any house to be looked at, and $\bar{V}$ is the value of the utility function found under the maximization procedure described in assumption 3 . The cumulative distribution of $f(V)$ is $F(V)$.

5. There are enough houses "on the market" at any given time so that the issue of waiting for more houses to appear does not arise."

6. There is a constant cost of looking at one house, denoted $c$.

It should be noted that although the market characterized by assumptions 1 to 6 is simple it is not degenerate. Given that buyers have different tastes over housing characteristics there will be a distribution of housing characteristics available in the market and hence a nondegenerate $f(V)$ facing each buyer. These distributions will not "spike" unless the market offers only one type of house.

At any stage of the search process, the value of the buyer's utility

"Of course, at some price, any house is "on the market." What is meant by that phrase in this context is that the owner is actively seeking to sell the house at the price $P \cdot H$. 
function as he contemplates making one more scarch is given by:

$$
V=\max \left\{\begin{array}{l}
V_{0} \\
-c+\left(1-F\left(V_{0}\right)\right) E\left(V \mid V \geq V_{0}\right)+V_{0} F\left(V_{0}\right)
\end{array}\right\} .
$$

In (2), $V_{0}$ is the utility associated with the best house that has been found thus far. The second line is the expected utility after one more search. It is the probability of finding a better house times the expected utility of better houses conditional on finding such a house, plus the probability of not doing better times the utility of not doing better (i.e., utility of the best house thus far found), minus the cost of search, defined in terms commensurate with utility. (Note that it is implicitly assumed that there is no cost of reserving the best house found thus far. If there were such a cost, the optimal stopping point, discussed below, would be further from $\bar{V}$.)

A rational buyer stops scarching when the first line of the right-hand side of (2) is equal to or greater than the second line. ${ }^{5}$ The two lines are equal when

$$
c=\int_{V_{0}}^{\bar{V}}\left(V-V_{0}\right) d F
$$

At this point, the expected gain in utility deriving from further search will be just equal to the loss in utility associated with the cost of search. Equation (3), for a given $f(V)$, will define an optimal $V_{0}$ at which to cease search. This value of $V_{0}$ will be denoted $V^{*}$.

The value of $V^{*}{ }_{i}$ for a given buyer $i$ depends on the form of $f_{i}\left(V_{i}\right)$, the value of $\bar{V}_{i}$, and the value of $\underline{V}_{i}$. Assuming that:

(1) utils are measured in dollars (and the marginal utility of income is constant in the range under consideration);

(2) the cost of search for a household looking at $\$ 30,000$ houses (houses with an annual value of $\$ 3000$ at a $10 \%$ discount rate), is $\$ 30.00$ per house searched;

(3) $\underline{V}$ is $\$ 2000$, implying that a buyer looking at houses with annual values of $\$ 3000$ will not look at something worth less than $\$ 2000$ to him; and

(4) the distribution of $f(V)$ is rectangular between $\underline{V}$ and $\bar{V}$; the value of $V^{*}$ is $\$ 2755$. This means that if one pays $\$ 30,000$ for a house, there is some house (which may or may not exist in fact) for which one would pay $\$ 2450$ more, with the same utility function and the same income, if the house could be found, but it is not worth looking for.

${ }^{5}$ This is the familiar sequential search rule derived in Rothschild [15]. 
While these assumptions are arbitrary, their end result seems to be plausible. People stop searching short of their "dream house," even if that dream is defined within a current budget constraint. The amount that they stop short, about $\$ 20$ per month in rental value for a family earning perhaps $\$ 15,000$ per year, is not unreasonable.

\subsection{Seller's Aversion in the Model}

Seller's aversion is introduced into the model with the following assumptions:

1. There are $n$ neighborhoods in a city, indexed $(j=1, \ldots, n)$.

2. For each neighborhood $j$ in the city in which there are whites who have houses for sale, blacks perceive that there is a nonzero probability $\left(\gamma_{j}\right)$ that whites in that neighborhood will be unwilling to sell to them at current market prices. ${ }^{6}$ The probability that blacks will be unwilling to sell to other blacks at current market prices is assumed zero. The probability that a black searching in neighborhood $j$ will find an averse seller, then, is $\gamma_{j}$ times the fraction of sellers in neighborhood $j$ who are white. This probability will be denoted $\alpha_{j}$.

3 . There is variation in $\alpha_{j}$ across the $n$ neighborhoods.

These assumptions are weak. Given an indexing of neighborhoods, they are met in all U. S. cities. Further, Schelling [16] has shown that a random distribution of households by race will not lead to uniform racial composition by neighborhood. Thus, given the existence of some whites who are unwilling to sell to blacks at a given set of market prices for housing, even a random distribution of the population by neighborhood will lead to variation of $\alpha$ across neighborhoods.

Without loss of generality, we may order the neighborhoods $j$ by their values of $\alpha$, such that $\alpha_{1} \leq \alpha_{2}, \ldots, \leq \alpha_{n}$, and $\alpha_{1}<\alpha_{n}$. Any black household $i$ contemplating search in the housing market will have the choice of searching in any of the $n$ neighborhoods. His utility at any state of the search process, analogous to Eq. (2) of the previous section of this paper, will be given by:

$$
V=\max \left\{\begin{array}{l}
V_{0} \\
-c_{1}+\left(1-\alpha_{1}\right)\left(1-F_{1}\left(V_{0}\right)\right) E\left(V_{1} \mid V_{1} \geq V_{0}\right)+\left(1-\alpha_{1}\right) V_{0} F_{1}\left(V_{0}\right)+\alpha_{1} V_{0} \\
-c_{2}+\left(1-\alpha_{2}\right)\left(1-F_{2}\left(V_{0}\right)\right) E\left(V_{2} \mid V_{2} \geq V_{0}\right)+\left(1-\alpha_{2}\right) V_{0} F_{2}\left(V_{0}\right)+\alpha_{2} V_{0} \\
\vdots \\
-c_{n}+\left(1-\alpha_{n}\right)\left(1-F_{n}\left(V_{0}\right)\right) E\left(V_{n} \mid V_{n} \geq V_{0}\right)+\left(1-\alpha_{n}\right) V_{0} F_{n}\left(V_{0}\right)+\alpha_{n} V_{0}
\end{array}\right\}
$$

where all terms are defined as before and subscripts denote neighborhoods.

- The value of $\gamma_{j}$ will in general be a function of market prices, among other things, and issues related to determination of $\gamma_{j}$ are discussed below. All that is necessary for the current argument, however, is that $\gamma_{j}$ be nonzero at prevailing market conditions. 
The effect of seller's aversion is to take $\alpha_{j}$ of the density $f_{j}(V)$ and put it at $V=0$. This reduces expected benefits of search in neighborhood $j$, or, alternatively, increases costs. On average, a black searching in ncighborhood $j$ will have to look at $1 / 1-\alpha_{j}$ houses for every house he has the option of purchasing. $V^{*}$ may be computed from the expression

$$
\frac{c_{j}}{1-\alpha_{j}}=\int_{V^{*} j}^{\bar{V}_{j}}\left(V_{j}-V^{*}{ }_{j}\right) d F_{j} .
$$

Consider (4) and (5) under the assumptions (to be relaxed later) that the distributions $f_{j}(V)$ are identical in all neighborhoods and that the cost of search is the same in all neighborhoods. Under these assumptions the effect of seller's aversion is that blacks never search for housing in neighborhoods with values of $\alpha$ greater than $\alpha_{1}$. Equations (4) and (5) may be rewritten as $\left(4^{\prime}\right)$ and $\left(5^{\prime}\right)$ :

$$
\begin{gathered}
V=\max \left\{\begin{array}{c}
V_{0} \\
-c+\left(1-\alpha_{1}\right)\left(1-F\left(V_{0}\right)\right) E\left(V \mid V \geq V_{0}\right)+\left(1-\alpha_{1}\right) V_{0} F\left(V_{0}\right)+\alpha_{1} V_{0} \\
\vdots \\
-c+\left(1-\alpha_{n}\right)\left(1-F\left(V_{0}\right)\right) E\left(V \mid V \geq V_{0}\right)+\left(1-\alpha_{n}\right) V_{0} F\left(V_{0}\right)+\alpha_{n} V_{0}
\end{array}\right\}, \\
\quad-\frac{c}{1-\alpha_{j}}=\int_{V^{*}{ }_{j}}^{\bar{V}}\left(V-V^{*}{ }_{j}\right) d F \quad(j=1, \ldots, n) .
\end{gathered}
$$

By inspection, for any value of $V_{0}$, the last $n$ lines of $\left(4^{\prime}\right)$ are strictly decreasing in $\alpha$, as is $V^{*}$ in Eq. $\left(5^{\prime}\right)$. Thus, if housing prices are identical in all neighborhoods, blacks will only search for housing (and only buy housing) in those neighborhoods where $\alpha$ is lowest. If there are any neighborhoods that are all black, blacks will search only in these neighborhoods, as the value of $\alpha$ in such neighborhoods is zero. Under these assumptions, then, as in Schelling's model, turnover in the housing market will lead to racially segregated neighborhoods, although not necessarily to a single "ghetto."

But prices need not be constant in all neighborhoods under these assumptions. In particular, any nonzero value of $\alpha$ greater than $\alpha_{1}$ will be consistent with a market equilibrium in which (1) neighborhood housing prices are a decreasing function of the value of $\alpha$ obtaining in the neighborhood; (2) blacks never search in neighborhoods with values of $\alpha$ greater than $\alpha_{1}$; such that (3) there is nothing to equilibrate prices in different neighborhoods at a uniform level.

The maximum equilibrium price differential between neighborhood 1 and neighborhood $j$ can be found as follows:

(1) In Eq. (4'), as in Eq. (2), solve for the value of $V^{*}$ that represents the optimal stopping point for search in neighborhood 1. 
(2) For a given value of $\alpha_{i}$ add to the distribution of utilities in neighborhood $j$ the utility of lower prices. Thus, still assuming that the distribution of utilities from the distribution of housing in the two neighborhoods is identical, if the distribution of utilities in neighborhood 1 is given by $\left(1-\alpha_{1}\right) f(V)$, the distribution in the neighborhood $j$ is given by $\left(1-\alpha_{j}\right) f\left(V+D_{j}\right)$, where $D_{j}$ is the utility of the difference in prices. Furthermore, while utilities in neighborhood 1 are distributed from $\underline{V}$ to $\bar{V}$, those of the neighborhood $j$ go from $\underline{V}+D_{j}$ to $\bar{V}+D_{j}$. Thus, the distribution in neighborhood $j$ is $f(V)$, reduced by the fraction $\left(1-\alpha_{j}\right)$, and shifted to the right by $D_{j}$.

(3) Substitute the value of $V^{*}{ }_{1}$ calculated in step (1) into the distribution of utilities found in step (2).

(4) Solve Eq. (6) for the value of $D_{j}$ at which $V^{*}$ will be equal in neighborhood $j$ and neighborhood 1:

$$
c=\left(1-\alpha_{j}\right) \int_{V^{*_{1}}}^{\bar{V}+D_{i}}\left(V-V^{*}\right) f\left(V+D_{j}\right) d V \quad(j=2, \ldots, n) .
$$

At these values of $D_{j}\left(\right.$ denoted $\left.D^{*}{ }_{j}\right)$, all searching strategies implicit in Eq. (4') will be just equal in utility when the value of the best house found during search is $V^{*}{ }_{1}$. At any value of $D_{j}$ less than $D^{*}$, search in neighborhoods where $\alpha$ is equal to $\alpha_{1}$ will dominate search in the neighborhood $j$. Furthermore, inspection of Eq. (6) makes it clear that $D^{*}{ }_{j}$ is an increasing function of $\alpha_{j}$. Thus three propositions are established under the assumptions of the model:

1. Seller's aversion, defined as the unwillingness of some whites to sell their houses directly to blacks under a given set of market conditions is consistent with a price differential in which housing is purchased by blacks in black neighborhoods at higher prices than those obtaining in white and integrated neighborhoods.

2. The maximum price differential is an increasing function of the fraction of white sellers in a neighborhood who are averse to dealing with blacks.

3. If the price differential obtaining in a neighborhood is less than the maximum, blacks will never search in that neighborhood, so there will be nothing to eliminate market segmentation by neighborhood racial composition.

It should be noted that these results do not imply that blacks will necessarily receive housing on terms inferior to those received by whites. They do imply that such differentials, within certain limits, will be consistent with equilibrium, and that the size of the maximum equilibrium differential, ceteris paribus, will be a monotone increasing function of the 
TABLF; 1

Relationships between $D^{*}$ wand $\alpha_{w}$ under Assumptions 2.1

\begin{tabular}{ccc}
$\alpha_{\mathrm{w}}$ & $D^{*}{ }_{\mathrm{w}}(\$)$ & $\begin{array}{c}D^{*} / \text { annual rental } \\
\text { value }=\$ 3000\end{array}$ \\
\hline 0.2 & 44 & 0.015 \\
0.5 & 101 & 0.053 \\
0.75 & 245 & 0.082 \\
0.9 & 797 & 0.270 \\
\hline
\end{tabular}

fraction of the white population which is averse to dealing with blacks. In other words, assuming that there exist all white and all black neighborhoods and that the value of $\alpha$ in all white neighborhoods is $\alpha_{\mathrm{w}}$, blacks will not search in white neighborhoods unless the price differential is greater than $D^{*}{ }_{\mathrm{w}}$. As long as $D_{\mathrm{w}}$ is less than $D^{*}{ }_{\mathrm{w}}$, the housing market will be "segmented" in that there will be geographically and economically. distinct racial submarkets.

The empirical importance of the result stated above cannot be evaluated without making assumptions about the functions and parameters involved. Making the same empirical assumptions as were made in Section 2.1, and assuming that there exist neighborhoods for which the value of $\alpha$ is zero, some relationships between $D^{*}{ }_{\mathrm{w}}$ and $\alpha_{\mathrm{w}}$ are seen in Table 1.

Thus, at least for the rectangular distribution and the parameters of the model used to obtain what appeared to be a plausible result in Section 2.1, the effect of the percentage of whites in all white neighborhoods unwilling to deal with blacks is striking. Not only can prejudice of this form affect the prices paid by blacks adversely, but a high incidence of prejudice will generate a great deal of adversity.

\section{IMPLICATIONS AND EXTENSIONS OH' 'THE MODEL}

\subsection{The Rate of Growth Hypothesis and Neighborhood Tipping}

Viewed in light of the search model presented above, the rate of growth hypothesis becomes plausible as a contributing factor to the establishment of equilibria in which blacks pay more for housing, rather than as a description of disequilibrium. As blacks migrated to northern cities, they had the option of searching for housing in the white or black neighborhoods. As long as $D_{\mathrm{w}}$ was less than $D^{*}$, they searched only in black neighborhoods. But migration and population growth increased the demand for housing in black neighborhoods, raising prices in these neighborhoods, leading to $D_{\mathrm{w}}$ greater than $D^{*}$ w, and inducing blacks to search in white neighborhoods. Blacks would then move into housing in 
heretofore white neighborhoods, but only as long as the price of housing in black neighborhoods was such that $D_{\mathrm{w}}$ was greater than $D^{*}$ w.

The model also sheds some light on the issue of neighborhood "tipping." Once blacks began purchasing housing in a given white neighborhood the value of $\alpha$ in that neighborhood would fall for two reasons. First, those whites who are averse to dealing with blacks are likely to be averse to living with them. They would thus have a strong incentive to sell to blacks in order to leave the neighborhood. As $\alpha$ was perceived by blacks to be falling, the neighborhood would become relatively more attractive for search, and prices would tend to risc toward black submarket prices, providing a monetary incentive for whites to sell to blacks. Thus once a neighborhood begins to "tip," both supply and demand considerations would enhance the process until equilibrium in the urban area was restored at a value of $D_{\mathrm{w}}$ equal to $D^{*}$ w. That such tipping would take place at locations adjacent to black neighborhoods is predicted by the "border" models of Bailey [1], Courant [3], Rose-Ackerman [14], and others, in which it is shown that white prejudice against living near blacks causes the price of housing in white neighborhoods to be lowest in border areas. (This has been confirmed by King and Mieszkowski's empirical study [10].) Thus, when $D_{\mathrm{w}}$ is greater than $D^{*}$ w, blacks will search first in border areas because the price differential between the black interior and other neighborhoods is largest in border areas. This will lead to expansion of the black neighborhoods at their borders so that such geographic segregation as exists can be expected to be preserved when the market adjusts to values of $D_{\mathrm{w}}$ greater than $D^{*}$ w.

\subsection{Self-Segregalion vs Rational Search}

Consider a stylized case in which there are white neighborhoods, border neighborhoods, and black neighborhoods. If whites in border neighborhoods are no more averse to dealing with blacks than whites in white neighborhoods, the value of $\alpha$ in border neighborhoods will be less than that in the white neighborhoods because border neighborhoods contain blacks and whites. Thus the value of $D^{*}$ in the border neighborhoods will be lower than $D^{*}$ w but greater than zero. If blacks are faced with identical distributions of utilities in the three types of neighborhoods, it would be consistent with equilibrium in the search model if prices paid by blacks were lower in border neighborhoods than in all black neighborhoods. King and Mieszkowski [10] found such a configuration of prices, and argued that their finding provided evidence of a black taste for selfsegregation. However, in the context of the search model, such a finding may be interpreted as the result of optimal search behavior on the part 
of black buyers (renters). This does not imply that blacks do not have a taste for self-segregation, but it does suggest a plausible altrornative explanation for King and Mieszkowski's findings.

\subsection{Different Utility Distributions}

Up to this point, it has been assumed that the distributions $f_{j}(V)$ are identical across neighborhoods. (see Eq. (4').) In the following discussion, that assumption is dropped, in which case the maximization problem for black searchers is that embodied in Eq. (4). However, the value of $D^{*}{ }_{j}$ which will equate the last $n$ lines of Eq. (4) will now depend on the distributions $f_{j}(V)$ as well as upon the values of $\alpha_{j}$.

Indeed, in an extreme case, blacks with certain tastes will have equilibrium values of $D^{*}$ that are zero or negative for some neighborhoods $j$. Under these circumstances, such blacks will search in the neighborhood where $D^{*}{ }_{j}$ is lowest $\left(V^{*}{ }_{j}\right.$ is highest) and will be willing to pay the same or higher prices for housing than those paid by whites. But they will not, in general, get as much for their money as whites. If we consider a white and a black with identical tastes, searching over the same distribution of houses in a white neighborhood $j$, the white's optimal stopping rule is defined by solving for $V^{*}$ such that

$$
c=\int_{V^{*}}^{\bar{V}}\left(V-V^{*}\right) d F_{j}
$$

The black's optimal stopping rule, however, will lead him to solve for $V^{*}$ such that

$$
\frac{c}{1-\alpha_{j}}=\int_{V^{*}}^{\bar{v}}\left(V-V^{*}\right) d F_{j} .
$$

Clearly, if $\alpha$ is positive, $V^{*}$ will be lower for the black. While projudice may or may not be reflected in housing prices in this case, it will affect the level of utility achieved by blacks. Such effects may be very difficult to measure in the market, but the model suggests that they exist, and, if $\alpha$ is large in neighborhoods where $f(V)$ is otherwise highly favorable for some blacks, these utility effects may be important.

Furthermore, in less extreme cases, the existence of a positive value of $\alpha$ will, over some range of differences in the distributions of utilities, induce blacks to limit their search to black neighborhoods even though the distributions of utility from housing that exists in white neighborhoods is more favorable. Here again, not all of the loss in utility will 
appear as a difference in market prices, although some of it will. In the special case where the distribution of utilities in a white neighborhood $j$ is just equal to the distribution in a black neighborhood shifted to the right by $D^{*}{ }_{j}$ and multiplied by $1-\alpha_{j}$, there will be no price differential, but whites will on average receive $D^{*}{ }_{j}$ more of utility than blacks with identical tastes. In the special case of Section 2.2, all of the utility difference is reflected in prices.

In any event, to the extent that the distribution of utilities derived from housing in some white neighborhoods is, in the absence of seller's aversion, more favorable than that found in black neighborhoods, the results of Section 2.2 concerning maximum equilibrium price differentials must be modified. The unfavorable terms on which blacks search in white neighborhoods need not lead to price differentials. However, such price differentials as are measured (including zero differentials) will, in general, understate the loss in black utility caused by white seller's aversion.

\section{INSTITUTIONS IN THE MARKET-REALTORS AND ARBITRAGEURS}

Although the modifications discussed above imply that there may not be price differentials for all types of housing, the unmodified model of Section 2.2 will apply where the distribution of housing types over which a buyer searches (both owner-occupied and rental) is similar in both black and white neighborhoods. For low and moderate income housing, it would appear that the unmodified model will be more applicable for many Northern cities. Given this, the question arises as to whether market specialists will find it profitable to engage in arbitrage activities such that price differentials cannot be maintained in long-run equilibrium. The issue at hand has been succinctly stated by Muth [11, p. 107] as follows:

\footnotetext{
... if real-estate agents fail to deal with potential Negro buyers because of their own preferences, they will make fewer sales and earn lower incomes. It would thus be in the interest of renters or sellers of real estate to sell out to others without an aversion to dealing with Negroes; by so doing they would increase their incomes, since potential buyers without these aversions would offer more than the capitalized value of the business to the landlords or realestate agents who are averse to dealing with Negroes.
}

The purpose of this section will be to show that in the context of a search model with racial prejudice there will be important market forces inhibiting both real estate agents and arbitrageurs (blockbustcrs) from capitalizing on the opportunities implicit in the above quotation. 


\subsection{Simple Arbitrage in the Search Model}

At least two important market forces tend to make arbitrage unprofitable in the owner-occupied market. The most obvious stems from the transactions costs of buying and selling housing. Less obvious are costs associated with persuading blacks to look for housing in a neighborhood where $\alpha$ has a high value. We deal with the latter problem first. (Again, the discussion will take place in the context of the owner-occupied market, although the mechanisms involved apply equally well to the rental market. Furthermore, in the rental market, there are additional costs of racial transition, if whites are prejudiced, which are examined in Yinger [17].)

Given that the effect of seller's aversion is to reduce the efficacy of search in white neighborhoods, if $D_{\mathrm{w}}$ is less than $D^{*}$ w for a given value of $\alpha_{w}$ blacks will not search in white neighborhoods at all, and the market will be segmented into racial submarkets. Thus, one problem confronting a middleman attempting arbitrage between black and white submarket prices will be to find and induce a buyer in the black submarket to look at housing in the white submarket in the first place. Indeed, given that the value of $D_{w}$ is less than $D^{*}$, the image of blacks frantically searching for housing in white neighborhoods, ready to jump out of the ghetto at any time, is quite misleading. In fact, rational black consumers of housing will never search in white neighborhoods, because it is not worth it to do so. An arbitrageur must overcome this problem in order to turn a profit. While it is difficult to estimate how expensive this difficulty will be in fact, it would seem that the necessary advertising costs (as well as social stigma associated with such advertising, in high $\alpha$ neighborhoods) could be considerable. Clearly, however, when $D_{\mathrm{w}}$ is greater than $D^{*}{ }_{\mathrm{w}}$, this will not be such a problem, and the action of such arbitrageurs will be equilibrating, subject to the qualifications deriving from standard transactions costs which are discussed below.

In order to ply his trade, the arbitrageur must buy a house, hold it, and sell it. In so doing, he incurs the purchase price in the white submarket, denoted $P_{\mathrm{w}} \cdot H$, for a given vector $H$, plus transactions costs borne by the buyer which are some fraction $t_{\mathrm{b}}$ of the purchase price. In addition, he foregoes the use of $\left(1+t_{\mathrm{b}}\right) P_{\mathrm{w}} \cdot H$ during the period when the house is on the market but not yet sold. In return for incurring these costs, he receives a maximum of $\left(P_{\mathrm{w}}+D\right) \cdot H$, minus any transaction costs $\left(t_{\mathrm{s}}\right)$ borne by the seller times the sales price. ( $D$ is measured here in money, rather than in utility, and is a vector of price differentials for the characteristics. Furthermore, the prices are capitalized asset prices rather than annual rental prices. Otherwise the notation follows that of Section 2.1) If $r$ is the interest rate, and $m$ the number of months he expects to 
hold the house before it is sold, profits on such a transaction will be

$$
\Pi=\left(1-t_{\mathrm{s}}\right)\left(P_{\mathrm{w}}+D\right) \cdot H-P_{\mathrm{w}} \cdot H\left(1+\frac{r m}{12}\right)\left(1+t_{\mathrm{b}}\right) \cdot^{7}
$$

If it is assumed that the arbitrageur uses none of his time, or values his time at zero, in making such transactions, the value of $D \cdot H$ at which such activity has zero profits will be the minimum value at which it will take place. Under what would seem to be fairly generous assumptions about the parameters affecting the profitability of such arbitrage, namely, that the $t^{\prime}$ s both equal 0.03 , that $r$ is 0.12 , and that $m$ is one month, profits will be zero when $D \cdot H / P_{\mathrm{w}} \cdot H$ is about 0.07 . In other words, the price differential hetween the two submarkets would have to be at least $7 \%$ of white prices before such arbitrage could be profitable. This is a rather large differential for a market to generate as a long-run equilibrium. Yct it would appear that there is nothing in the market to make it or its welfare implications go away.

Furthermore, in those cases where the distribution of utilities in the white submarket is more favorable than in the black, the thing to be arbitraged is utility, and not prices. It is hard to conceive of an economic mechanism that would do the job.

\subsection{Real Estate Agents in a Search Model}

Two sets of considerations tend to prevent the activities of real estate agents from eliminating price differentials deriving from the search models of Section 2. One is idealogical, and has been documented by Helper [5], Yinger [18], and the National Academy of Sciences [12], among others. A generous interpretation of the professional ideology of real estate brokers regarding racial integration is that it is a violation of professional ethics to introduce a black into a white neighborhood if the agent perceives that the result will simply be to leave everyone unhappy with his neighbors. ${ }^{8}$ Somewhat less generously interpreted, the ideology is racist.

Reinforcing these ideological considerations are direct economic reasons to prevent realtors from introducing blacks into neighborhoods where $\alpha$ is

${ }^{7}$ For a landlord, the situation is somewhat different, as he will receive rents while the racial composition of occupancy changes. Thus the opportunity costs term will not be as large. However, the loss in white rentals due to white prejudice has no analog for the owner-occupier case. (see Yinger [17]). The net effect of these two phenomena may be either positive or negative, but, in any event, as is seen below, the opportunity cost term is unimportant, relative to transactions costs, for plausible parameters of Eq. (9).

${ }^{8} \mathrm{I}$ am indebted to Jerome Rothenberg for this formulation. 
high, assuming that $\alpha$ is a good index of the ractal preforences of the neighborhood. The following example will serve to illustrate these.

Assume that realtors have good information about the distribution of housing characteristics and about the racial preferences of whites in particular neighborhoods. Assume further that the housing market is organized as in Section 2.2, that the value of $D_{w}$ is not high enough to make arbitrage profitable, that the value of $D_{\mathrm{w}}$ is less than $D^{*}$ w and that information about the aversion or absence thereof of individual scllers is not coded into the multiple listing file. Recall that when there is multiple listing the commission is divided between the listing agent and the selling agent, who may be the same person.

Under these conditions, neither the listing agent nor the selling agent has an incentive to show housing in white neighborhoods to blacks. The listing agent would incur the enmity of the neighborhood, and, as reputation and referals are an agent's stock in trade, at least as far as getting future listings goes, it is difficult to see how the value of finding a buyer for one transaction which is expected to occur in any event could outweigh the loss of potential future business which would accompany such a transaction. The selling agent, even if he does not expect to obtain listings in the neighborhood and is therefore not directly concerned with local opinions of his behavior, perceives a number of obstacles to showing a house in a white neighborhoud to blacks. First, he has to confront the same search problem faced by a buyer in the simple model of Section $2-$ he knows the probability that a sale can be made to his client, but does not know with certainty that such a sale can be made. Second, he is concerned with the reputation of realtors generally, as, under multiple listing, the fraction of transactions in the city which are made through realtors is important to all realtors. Finally, it is valuable to realtors to be on good terms with other realtors. Yinger [18] cites a number of studies which document situations in which realtors have "punished" other realtors for introducing or attempting to introduce blacks into white neighborhoods.

The possibility that the preferenees of the individual seller will in fact be coded into the multiple listing file changes this analysis rather little. Given that the listing agent in a high $\alpha$ neighborhood does not want the house shown to blacks his behavior will depend on whether he believes that subscribers to the multiple listing file will "honor" his wishes. If he believes that they will do so, he can simply code all listings as being "whites only," regardless of his client's wishes. If he believes that some of his competitors would show the house to a black in spite of his injunction not to, it is in his interest to simply not code racial preference at all, returning the selling agents to the case discussed above. 


\section{CONCLUSIONS AND IMPLICATIONS}

Given that there is seller's aversion on the part of some whites, and that blacks incur costs in searching for housing, the following results have been established:

(1) Where the housing stock over which blacks search is similar in both black and white neighborhoods, there can exist a long-run equilibrium in which blacks pay more for housing than whites and do not search in white neighborhoods. Thus the market can remain segmented in a long-run competitive equilibrium. This conclusion differs from that of Kain and Quigley in that segmentation in their work is directly assumed. Here it is shown to be consistent with the workings of a competitive housing market.

(2) The transactions costs involved in the housing market are such that racial price differentials will not, in general, be arbitraged away, although arbitrage will place an upper limit on the maximum equilibrium differential.

(3) There are a number of reasons, both economic and sociological, to expect that the real estate brokerage industry will not act so as to eliminate such differentials.

(4) Whether or not arbitrageurs and real estate brokers act so as to eliminate such differentials in the price dimension, blacks whose utility distributions are more favorable in the white submarket than in the black will receive, in long-run equilibrium, less utility from housing than will identical whites. There is no plausible market mechanism which will eliminate such utility differentials.

The welfare implications of these results are quite serious, especially when they are compared with the welfare implications of other economic models of racial prejudice in housing markets. In virtually all of the earlier published models, long-run equilibrium can be characterized as a situation in which whites pay for their prejudice, in that they receive housing on terms relatively less favorable than those obtaining in a nonprejudiced equilibrium, and blacks receive housing on terms relatively more favorable than those implicit in a nonprejudiced equilibrium. The models presented here imply that just the opposite situation may occur.

Furthermore, the increasing upward mobility of blacks will tend to accentuate the difficulties faced by blacks in obtaining housing on terms equal to those obtained by whites. As long as blacks are searching in a lower middle income market, where the distribution of houses available in the white and black submarkets is essentially similar, there is at least the possibility that arbitrage and the actions of some brokers will tend to place upper limits on price differentials and perhaps even bid them 
away. Indeed, in cases there where the distribution of housing characteristics is intrinsically more favorable in black neighborhoods, and whites do not compete for housing in such neighborhoods, it may be that blacks can obtain such housing on nondiscriminatory terms.

For those (presumably more affluent) blacks for whom the distribution of housing characteristics is relatively favorable in white neighborhoods, however, there will be no market mechanisms operating to provide them the housing which is best suited to their preferences on the same terms that such housing is available to whites. This will have two serious consequences. First, such blacks will enjoy less utility in the market. Second, they will stay in the black submarket, competing for housing better suited to less affluent blacks, unless the distribution of utilities in the white submarket is substantially more favorable than that in the black submarket. In so doing, they themselves will receive housing less suited to their tastes than they would if there were no seller's aversion, and they will also bid up the price of housing available to other blacks, reducing their utility as well.

This paper has developed a model of the housing market in which racial segmentation of submarkets, resulting in blacks receiving housing on relatively unfavorable terms, can result as a consequence of rational behavior in a competitive market. This is in direct contradiction to competitive models of housing markets with racial projudice found in the earlier literature on the subject. Unfortunately, this paper is in direct conflict with those models in another sense as well. They imply that racial justice will eventually obtain as a result of the working of natural market forces. There is no such comforting implication to be found in the work reported upon here.

\section{REFERENCES}

1. M. Bailey, A note on the economics of residential zoning and urban renewal, Land Economics (August 1959).

2. G. Becker, "The Economics of Discrimination," Univ. of Chicago Press, Chicago (1957).

3. P. N. Courant, "Economic Aspects of Racial Prejudice in Urban Housing Markets," unpublished Ph.D. Dissertation, Princeton University (1973).

4. P. N. Courant and J. Yinger, On models of racial prejudice and urban residential structure, J. Urban Econ. 4, 272-291 (1977).

5. R. Helper, "Racial Policies and Practices of Real Estate Brokers," University of Minnesota Press, Minneapolis (1969).

6. R. Haugen and A. Heins, A market separation theory of rent differentials in metropolitan areas, Quart. J. Econ. (November 1969).

7. J. Kain, "The Effect of Housing Market Segregation on Urban Development," U. S. Savings and Loan League, Conference on Savings and Residential Financing (1969), 
8. J. Kain and J. Quigley, Measuring the value of housing quality, J. Amer. Statist. Assoc. (June 1970).

9. J. Kain and J. Quigley, "Housing Markets and Racial Discrimination," National Bureau of Economic Research (1975).

10. T. King and P. Mieszkowski, Racial discrimination, segregation and the price of housing, J. Political Econ. (May/June 1973).

11. R. Muth, "Cities and Housing," Univ. of Chicago Press, Chicago (1969).

12. National Academy of Sciences, "Freedom of Choice in Housing: Opportunities and Constraints" (1972).

13. C. Rapkin, Price discrimination against negroes in the rental housing market, in "Essays in Urban Land Economics," Real Estate Research Program, UCLA (1966).

14. S. Rose-Ackerman, Racism and urban structure, J. Urban Econ. (January 1975).

15. M. Rothschild, Models of market organization with imperfect information : a survey, J. Political Econ. (November/December 1973).

16. T. Schelling, "Models of Segregation," Rand Corp. (1969).

17. J. Yinger, "A Model of Discrimination by Landlords," Institute for Research on Poverty, Discussion Paper, University of Wisconsin (1975).

18. J. Yinger, "An Analysis of Discrimination by Real Estate Brokers," Institute for Research on Poverty, Discussion Paper, University of Wisconsin (1975). 